\title{
Fortalecimiento del proceso lectoescritor mediante el método Glenn Doman y participación de los padres, en estudiantes de grado primero del colegio Gonzálo Rivera Laguado
}

Strengthening of the reading and writing process through the Glenn Doman method and parental involvement, in first grade students of the Gonzálo Rivera Laguado School

Fortalecimento do processo de leitura e escrita através do método de Glenn Doman e envolvimento dos pais, em alunos da primeira série da escola Gonzalo Rivera Laguado

\author{
Yashin Smith Moreno Moreno \\ Candidato a magister en educación \\ Universidad Autónoma de Bucaramanga \\ ymoreno620@unab.edu.co \\ María Eugenia Serrano Acevedo \\ Candidata a doctora en educación con énfasis en mediación pedagógica \\ Universidad Autónoma de Bucaramanga \\ mserran5@unab.edu.co
}

\section{Resumen}

La presente investigación tuvo como objetivo general fortalecer el proceso lectoescritor mediante el método Glenn Doman con participación de los padres, en estudiantes de grado primero del colegio Gonzalo Rivera Laguado, Cúcuta, Colombia. Este estudio corresponde a una investigaciónacción participante, conformada en capítulos que demuestran la problemática y sus respectivas soluciones. El diseño de la investigación se desarrolló través de las siguientes etapas: Construcción de la ruta de trabajo y diseño de instrumentos, entrevista informantes claves e interpretación de la información, la cual se llevó a cabo mediante la categorización inicial y emergente, la población general del Colegio Consta de 1173 estudiantes, para el estudio en cuestión la población estuvo representada por 29 estudiantes cursantes del grado primero, y proporcionalmente la cantidad 
de padres y representantes, la muestra fue de seis padres de familia igualmente para el caso de los estudiantes. Se fortaleció el proceso lecto escritor de los estudiantes incrementando su capacidad comprensiva para dar lectura y escritura a palabras y oraciones mediante el método Glen Doman, paralelamente se incrementaron las acciones participativas de los padres de familia, demostrando que las estrategias didácticas implementadas en la propuesta influyen significativamente en la apropiación del método y la contribución de técnicas de enseñanza aplicadas en el hogar. Finalmente, se socializaron los resultados del proyecto con la comunidad educativa y se dejó el proyecto inmerso en un plan de mejoramiento institucional que será implementado en todas las áreas, cursos y sedes de la Institución Educativa.

Palabras clave: Lectoescritura, estrategias pedagógicas, integración. Método Glenn Doman.

\begin{abstract}
The main objective of the present research was to strengthen the literacy process through the Glenn Doman method with parental participation, in first grade students of the Gonzalo Rivera Laguado School, Cúcuta, Colombia. This study corresponds to a participant research-action, formed in chapters that demonstrate the problem and their respective solutions. The design of the research was developed through the following stages: Construction of the work route and design of instruments, interviewing key informants and interpretation of the information, which was carried out through the initial and emerging categorization, the general population of the School Consists of 1173 students, for the study in question the population was represented by 29 students attending the first grade, and proportionally the number of parents and representatives, the sample was six parents equally for the case of students. The reading process of the students was strengthened by increasing their comprehension capacity to read and write words and sentences using the Glen Doman method, while the participative actions of the parents increased, demonstrating that the teaching strategies implemented in the proposal influence significantly in the appropriation of the method and the contribution of teaching techniques applied in the home. Finally, the results of the project were socialized with the educational community and the project was left immersed in an institutional improvement plan that will be implemented in all the areas, courses and venues of the Educational Institution.
\end{abstract}

Keywords: Literacy, pedagogical strategies, integration. Glenn Doman method. 


\section{Resumo}

O objetivo principal da presente pesquisa foi fortalecer o processo de alfabetização através do método de Glenn Doman com participação parental, em alunos da primeira série da Escola Laguado Gonzalo Rivera, Cúcuta, Colômbia. Este estudo corresponde a uma pesquisa-ação participante, formada em capítulos que demonstram o problema e suas respectivas soluções. O projeto de pesquisa através dos seguintes passos foram desenvolvidos: Construção caminho de trabalho e design instrumento, informantes-chave entrevista e interpretação da informação, que foi realizada por categorização inicial e emergente, a população em geral Escola Constituída por 1173 alunos, para o estudo em questão a população foi representada por 29 alunos da primeira série e, proporcionalmente, o número de pais e representantes, a amostra foi de seis pais igualmente para o caso dos alunos. os alunos escritor processo de alfabetização reforçadas, aumentando a sua capacidade global de ler e escrever palavras e frases por método Glen Doman, ações participativas paralelas de pais aumentou, demonstrando que as estratégias de ensino implementadas na influência proposta significativamente na apropriação do método e na contribuição das técnicas de ensino aplicadas em casa. Finalmente, os resultados do projeto foram socializados com a comunidade educacional e o projeto foi deixado imerso em um plano de melhoria institucional que será implementado em todas as áreas, cursos e locais da Instituição Educacional.

Palavras-chave: Alfabetização, estratégias pedagógicas, integração. Método de Glenn Doman.

\section{Introducción}

La primera infancia es la etapa más importante en la vida, es el período en el que se realizan las conexiones neuronales y se potencian las percepciones, Craig y Baucum (2001) destacan que es el "proceso activo que consiste en interpretar la información proveniente de los sentidos" (p. 140), se destaca la relevancia de adoptar criterios definidos para desarrollar las capacidades de los niños y las niñas, por ende, la educación primaria, juega el papel más importante en la formación, estimulación de habilidades y destrezas, así como la integración personal y social.

Actualmente, según un estudio realizado por la revista semana, Rojas (2013), señala que en 47 naciones Colombia es el país donde la gente se casa menos, apenas la mitad de los hogares tienen a los dos padres y 40 por ciento de los niños vive con otras personas, ante esta realidad la familia colombiana cuenta con una imagen bien sea la madre, el padre o la abuela. La falta de consolidación de la estructura funcional y de otros fenómenos económicos de la familia permite 
que en ciertos momentos no pueden estar pendientes de las actividades $\mathrm{O}$ compromisos escolares y el rendimiento académico de sus representados; porque éstos son los responsables del sustento económico. Los padres y representantes generalmente, presentan bajo o escaso apoyo a necesidades, intereses y avances escolares de sus hijos, desencadenando limitaciones para el desarrollo básico de la lectura y la escritura.

\section{Situación problémica}

En el recorrido de la historia educativa colombiana se observa el interés por incluir nuevos actores como parte del desarrollo formativo de los niños y niñas. Sin embargo, los resultados derivados de las más recientes encuestas nacionales de hábitos de lectura y consumo del libro de la CERLALC UNESCO (2012), señalan que Colombia ocupa un muy bajo lugar en cuanto a número de libros leídos por habitante: mientras en Argentina se leen 4.6 libros por habitante, en Colombia se leen 2.2, en Brasil 4.0 y en Chile 5.4. El índice de lectura ha bajado en Colombia, es decir, se lee cada vez menos. Claramente, las noticias y las cifras, se debe aceptar no es un país lector: se compran pocos libros, se lee muy poco y no se entiende lo que se lee. En todos los casos el docente tiene una función primordial pues es considerado el actor principal, prácticamente descargando toda la responsabilidad en éste, o en la institución, acerca de la formación de los estudiantes para impulsar la lectura y por ende la escritura. Mediante socializaciones diarias se logró identificar que los estudiantes no poseían elementos cognitivos para la compresión motivado a la poca participación de los padres de familia en el proceso de enseñanza aprendizaje trayendo como consecuencias las dificultades de los niños en el proceso lectoescritor por la falta de apoyo y de implicación de los padres en el proceso. Coincide con lo expuesto por la Organización de las Naciones Unidas para la Educación, la Ciencia y la Cultura (UNESCO) (2014): Cuando los padres de familia y los miembros de la comunidad se involucran en las actividades de la escuela, los estudiantes alcanzan mejores resultados, la asistencia a clases aumenta y la deserción escolar disminuye. Si los padres de familia generan expectativas claras respecto de sus hijos, apoyan con éxito su progreso en los estudios, lo cual implica que les transmiten su ánimo y aspiraciones personales con influencia en sus logros de aprendizaje. (p. 23). En relación con el planteamiento descrito, para el docente es importarte conocer si podrán fortalecer los procesos de lectoescritura mediante el método Glenn Doman con participación de los padres, en estudiantes de grado primero del colegio Gonzalo Rivera. 


\section{Objetivos de la investigación}

\section{Objetivo general}

Fortalecer el proceso lectoescritor mediante el método Glenn Doman con participación de los padres, en estudiantes de grado primero del colegio Gonzalo Rivera Laguado.

\section{Objetivos específicos}

Identificar falencias en el proceso lectoescritor de los estudiantes de primer grado del Colegio Gonzalo Rivera Laguado, Cúcuta, Colombia.

Identificar el conocimiento que poseen los padres de familia acerca del método Glenn Doman aplicado a la lectoescritura.

Diseñar estrategias didácticas centradas en el método Glenn Doman, para el mejoramiento del proceso lectoescritor en los estudiantes del Colegio Gonzalo Rivera Laguado, Cúcuta, Colombia con el apoyo de los padres de familia.

Implementar y validar las estrategias didácticas dirigidas a los estudiantes y padres de familia para consolidar el proceso lectoescritor.

\section{Estado del arte}

Importancia de la participación de los padres en el proceso de aprendizaje de los estudiantes
Según Colina (2012), en el proceso de aprendizaje están involucrados tres sujetos interactuantes: Padres-HijosDocentes, cuyas acciones deben estar integradas entre sí. Por ejemplo, a los docentes les corresponde orientar a los padres y prevenirlos de los posibles factores que pueden entorpecer $u$ obstaculizar el progreso escolar del niño en su proceso de aprendizaje. En tal sentido, es función de los padres crear un ambiente que estimule el aprendizaje, implementar métodos que animen a sus hijos a adquirir hábitos de estudio adecuados, conscientes de sus propios intereses y motivaciones.

Se hace evidente que, la participación de los padres en el proceso educativo de sus hijos favorece el crecimiento personal de ellos mismos, así como de los niños y el docente. Si éste último cuenta con la ayuda de los padres y se comparte con ellos el conocimiento del niño y los esfuerzos para facilitar el aprendizaje y desarrollo, las posibilidades de éxito por parte del niño en sus primeros pasos en la educación, aumentarán considerablemente.

Igualmente, Meval (1996), señala que los padres deben tomar las medidas necesarias para que exista en el hogar un ambiente adecuado y agradable para el estudio de su hijo, un rincón calmo y confortable que sea suyo y donde pueda dedicarse a las tareas escolares. Asimismo, tomando en cuenta que 
los padres constituyen el nexo natural entre la escuela y los otros miembros adultos de la comunidad, deben estar en interacción permanente con el personal de la institución. Por tanto, es necesario crear ámbitos que permitan a los docentes, padres $y$ representantes a reflexionar conjuntamente sobre la participación de los mismos en el progreso escolar de sus hijos, así como también lograr coherencia entre las pautas educativas del hogar y la escuela.

\section{Rol de los padres de familia en el proceso de aprendizaje de los estudiantes}

Según Hohmann, M. y Weikart, D. (2005), la participación de los padres en el proceso de aprendizaje de sus hijos es importante porque ellos no pueden ni deben dejar de ser copartícipes en la responsabilidad de educar a sus hijos; es preciso recordar que la familia y la comunidad moldean la personalidad del niño antes de que la escuela tenga alguna oportunidad de actuar. También señala el autor antes referido, que dentro de la familia $y$ en sociedades, la participación de la madre cumple un rol fundamental, pues a ella se le asignan las tareas referidas a la crianza de los hijos, para los cuales es el adulto socialmente significativo. Si esto es aceptado, también debe aceptarse que entre sus tareas estará el velar por lo concerniente a la educación de los hijos, lo cual incluye su cooperación a diferentes niveles en ese proceso formativo.
Sin embrago, aunque por todo esto, la participación de la madre es fundamental $y$ la que probablemente ocurre con más frecuencia, es importante que la escuela adopte medidas para promover igualmente la participación del padre, intentando así romper con un esquema según el cual a éste corresponden casi exclusivamente las tareas relativas al sostenimiento de la familia y al status de la misma.

Al respecto, Ochoa (1994), señala que de la integración hogarescuela pueden derivarse, entre otros, beneficios sociales y académicos. Sociales porque podrían disminuir el peligro de contradicción en los sistemas escolar y familiar, conectando el aprendizaje con la realidad del educando haciendo que marchen ajustadamente; académicos, dado que la participación de los padres debe alcanzar los aspectos pedagógicos de la formación del educando.

\section{Aprendizajes del niño en la familia}

Según Kallarakal (1997) en la familia el niño aprende el lenguaje y los gestos simbólicos; organizaciones del tiempo y el espacio; el uso de la memoria; el proceso de clasificación y evaluación; la enseñanza de economía y la política, la gratificación efectiva, la comprensión de la estructura social. También señala la autora antes referida, que la familia cumple un papel esencial en el 
proceso educativo general del niño, de cada individuo, es como un filtro de las experiencias educativas sancionando o aprobando conductas de manera cotidiana. La familia educa a sus miembros en las importantes nociones de tiempo y espacio. El espacio interpersonal y el espacio físico que permiten reconocer la distancia a la cual nos relacionamos con las diferentes personas, es cuidadosamente enseñado en el hogar.

La familia debería formar a sus hijos para tratar de despertar en ellos el sentido crítico para que sepan diferenciar el bien del mal, lo necesario de lo superfluo, lo principal de lo accesorio. Ayudarles a valorar toda la información que puedan recibir a través de los medios de comunicación: cine, radio, televisión, prensa, libros. Prepararlos para que puedan hacer uso adecuado de todas las invocaciones que se deben a los inventos humanos.

También señala el autor antes referido, que la familia es considerada como el núcleo del desarrollo educativo. Ella ayuda al niño para organizar las actividades. Las primeras experiencias de cada ser humano transcurren en el seno de alguna forma de organización familiar. Esta, también puede ser fuente de estímulo y capacidad de independencia o de represión y sumisión.

\section{Desinterés familiar y su influencia en el aprendizaje del lenguaje del estudiante}

El aprendizaje del leguaje requiere de una labor integral entre la escuela y la familia, algo que no suele suceder en entornos desfavorecidos y deja a los niños en desventaja desde sus inicios escolares. La práctica permanente de la lectura y la escritura es la clave para la perfección. La escuela tiene muchas limitantes para lograr que todos los estudiantes puedan aprender el contenido total del currículo por lo que es de suma importancia para el estudiante contar con el apoyo del hogar, algo que sucede frecuentemente en las clases medias y altas, que incluso sobrecargan a sus hijos con clases fuera del horario escolar.

Señala Arnaiz (2003) que el apoyo externo resulta imprescindible, y que aún aquellas personas sin una cualificación profesional específica, pueden ejercer una importante labor de apoyo al estudiante, y muchas veces al profesorado y añade que la familia que muchas veces es olvidada debe ser tomada en cuenta y contar con la colaboración de los padres en la escuela.

\section{Perspectiva teórica del aprendizaje para la implementación del método Glenn Doman}

El marco de referencia que sirve de sustentación de esta investigación está relacionado con las condiciones que proporciona la 
producción de cambio psicológico estable en situaciones educativas. Centra su atención en el proceso de enseñanza-aprendizaje, en la naturaleza de aquellas variables que afectan la adquisición y retención de cuerpos organizados de conocimiento a nivel mental y cognitivo en la implementación del Método Glenn Doman, el mejoramiento de las capacidades para aprender, la adquisición de motivaciones y actitudes por los estudiantes.

Dentro de este marco de referencia, se destaca el constructivismo, debido a que permite incluir los aportes de diversas teorías psicológicas que participan de muchos principios comunes. Básicamente, el constructivismo postula que toda persona construye su propio conocimiento tomando de su ambiente los elementos que su estructura cognoscitiva sea capaz de asimilar. El mismo principio de construcción es válido para el afectivo: es así como mediante interacciones constructivas con objetos de su medio, pero sobre todo con otras personas, por ejemplo, con sus padres, el estudiante se va desarrollando como un ser autónomo, moral, social e intelectual. Es por esta razón que la participación de los padres en el proceso de aprendizaje de sus hijos es fundamental para alcanzar un mayor rendimiento.

\section{Teoría del constructivismo social de Vygotsky}

Santrock J. (2004) afirma, que los enfoques constructivistas dan importancia a los contextos sociales del aprendizaje y aseguran que el conocimiento se construye progresivamente. La teoría del constructivismo social de Vygotsky es particularmente relevante para la presente investigación, ya que para este autor el niño es un ser social inmerso en interacciones sociales en un contexto socio-histórico y en actividades socioculturales. Según Vygotsky, los individuos construyen el conocimiento por medio de las relaciones con los demás siendo influenciado por la cultura en la que vive.

La teoría de Vygotsky ha originado gran interés con relación a que el conocimiento es situado y colaborativo, lo cual significa que el conocimiento se encuentra entre las personas $y$ el entorno, incluyendo objetos, herramientas, libros y las comunidades donde viven los individuos. Esto conduce a un mayor avance del conocimiento, por medio de la interacción con los individuos en actividades cooperativas. Estas ideas manifiestan que el funcionamiento cognitivo tiene orígenes sociales, una de las ideas más relevantes de Vygotsky es su concepto de la zona de desarrollo próximo. 
Métodos para que los niños y niñas aprendan a leer

Garabaya (2013), señala que son varios los métodos para que los niños y las niñas aprendan a leer en un idioma, así también se pueden usar para enseñar un segundo o un tercer idioma. El método sintético es el tradicional para que aprendan a leer, pero también existen otros como el analítico conocido como global y el de Glenn Doman, cuyos excelentes resultados están reconocidos ya en todo el mundo.

a. Método sintético: es el primer método usado en el campo educativo $y$ el que todo docente debe conocer, se trata de iniciar la enseñanza de las partes para conseguir un objetivo global, por tanto, lo primero que se enseñará a los niños es el abecedario se empieza por las vocales y a la vez que se practica la grafología de las mismas, una vez que conoce y domina las diferentes letras, se introducen los sonidos (fonemas) para que puedan identificar que sonido tienen las mismas al momento de juntarse con otras.

El siguiente paso será aprender las palabras y acabar en las frases, en definición, se inicia por analizar de la parte más pequeña de la palabra hasta llegar a las formas más complejas que son las frases. En algunos casos, se pueden empezar con silabas en vez de letras, de esta manera, podrán llegar a ser capaces de leer por sí mismos cuentos, poemas o fábulas.

b. Método analítico para la lectura infantil: El método analítico persigue el objetivo de que el niño y la niña sea capaz de leer. Para ello, se apoya de lo visual y en la relación de imágenes con palabras, la enseñanza de la lectura pasa de conocer las estructuras y el todo hasta llegar a las letras, trata de ser un método más dinámico que el sintético y además estimula más la lógica del niño y la niña. Este método se suele aplicar al haber cumplido los tres años y su fundamento radica en la asociación de palabras y textos con imágenes, por lo cual hay muchos niños que antes de aprender a leer son capaces de identificar marcas comerciales que han visto a diario por el entorno que les rodea, o incluso algunos eslóganes cortos, con lo que para este método, se trata de trabajar con bits de inteligencia se empieza con las palabras que más familiares les resulten a los niños como su nombre, mamá, papá, y seguir con palabras de la vida cotidiana, como mesa ventana, la mejor ayuda para el método es la utilización de fichas y murales en la clase.

c. Método Glenn Doman: Este es uno de los métodos mejor reconocidos, fue creado en 
los años 50 por Glenn Doman y se podría definir como el autor principal del método analítico, ya que su fundamento es la relación de imágenes y sonidos. Fue el creador de los bits de inteligencia, fichas de alta simplicidad con fondos blancos (para que el niño no pierda su atención en detalles sin importancia). El propósito es conseguir que el niño y la niña relacionen las imágenes con las palabras.

\section{El proceso de lectura y escritura como herramienta educativa mediante el método de Glenn Doman}

Es una metodología creada por Glen Doman, en Filadelfia en el año 1950 , los bits fueron creados por Glen Doman en Estados Unidos de Norteamérica, con la finalidad de estimular el desarrollo cerebral de los niños pequeños. Inicialmente fueron trabajados con niños que sufrían de lesiones cerebrales los resultados fueron tan positivos, que no tardaron los bits de inteligencia en introducirse en la escuela. El método bits de inteligencia es un magnífico instrumento educativo, donde los niños podrán apreciar estímulos diversos, tales como: aves, dinosaurios, mapas, señales de tránsito, entre otras cosas. Actualmente, son utilizados en distintos países de América, Europa y el resto del mundo.

Se presentan en mayor cantidad de áreas y categorías, ya que cada estímulo visual, adecuadamente presentado, facilita el mayor número de interconexiones nerviosas, que generan el desarrollo cerebral, el cual se traduce en mayor nivel intelectual.

El problema de las tarjetas de aprendizaje ha sido que siempre se enseñan los mismos estímulos, de esta manera el niño puede pasar toda su educación primaria, viendo los mismos contenidos y por consiguiente, sin propiciar nuevas interconexiones nerviosas. Es importante que las unidades de inteligencia no solo beneficien directamente a los niños, sino también a los docentes del grado primero, quienes serán las principales facilitadoras para que los niños reciban adecuadamente los estímulos; es por esta razón, la importancia de una adecuada capacitación para las mismas.

La peculiaridad de esta terapia consiste en trabajarlo en casa del niño en un ambiente familiar. Trabajar con el niño de manera que sea voluntariamente, sea la hora de su tiempo libre, pero siempre con buena predisposición del pequeño. La filosofía del tratamiento terapéutico propuesta por Doman, se basa en técnicas apropiadas de estimulación sensorial. Este método Doman consiste en desarrollar las habilidades y potencialidades de los niños haciendo uso de la memoria, sensaciones y percepciones, proporcionándoles información suficiente de calidad que despierte el interés y desarrolle la inteligencia de dichos niños. El 
método Doman se fundamenta en los principios neurológicos de la ciencia y utiliza como estrategia a los bits de inteligencia.

\section{Marco legal}

El Ministerio de Educación, teniendo como marco la normatividad colombiana desde la Constitución Política Nacional, el Código de infancia y Adolescencia (Ley 1098/2010) y la Ley de Protección Integral a la Familia (Ley1361 de 2009), Por su parte el Decreto 1286 de 2005, Por el cual se establecen normas sobre la participación de los padres de familia en el mejoramiento de los procesos educativos de los establecimientos oficiales y privados, señala en sus artículos 2 y 3 los deberes y derechos de los padres de familia.

\section{Diseño metodológico}

\section{Tipo de investigación}

La presente investigación, se diseña una propuesta didáctica para el fortalecimiento del proceso lectoescritor en los estudiantes de primer grado del colegio Gonzalo Rivera Laguado, Cúcuta, Colombia a través de la aplicación del método Doman y la integración de los padres de familia en el proceso. Se determina el estudio bajo el paradigma cualitativo, dentro de la modalidad de investigación de campo, con un carácter descriptivo, de tipo InvestigaciónAcción; pues la misma, fue dirigida a proponer estrategias didácticas como técnicas para la incorporación de los padres de familia al proceso de enseñanza y aprendizaje de los estudiantes inmersos en el estudio planteado.

\section{Población de la investigación}

El criterio de selección que se utilizó es el método de selección intencional, que es definido por Sabino (1996) como: "el criterio que toma el investigador, para la búsqueda de los participantes en la investigación que más le convengan en el desarrollo del estudio". (p.123). En consecuencia y tomando lo dicho por el autor, de una población general de la institución de 1173 estudiantes, la selección de los participantes en la investigación se tomó a los niños de grado primero, con criterio de selección de 29 estudiantes con padres de familia, a las muestras fueron de 6 estudiantes y 6 padres, para un total de 12 , mediante una la intencionalidad según acuerdo de los mismos padres. Los estudiantes son los que dan testimonio y evidencia según su rendimiento académico y se incluyen en su totalidad, para analizar los procesos de enseñanza-aprendizaje de la lectoescritura.

\section{Técnica e instrumento de recolección de datos}

Para la recolección de datos a fin de lograr los objetivos propuestos en el transcurso de la investigación, se desarrollan mediante los planteamientos apoyados en Flirk (ob. cit.), quien sugiere que: "el investigador 
observador forme parte activa de la experiencia, se ubique dentro del grupo y comparta con él las diferentes actividades que se realicen" (p.68). El autor de la presente investigación, se encuentra activamente vinculado a la institución por lo que se facilita el intercambio de información y experiencias y además fue el facilitador de los talleres de formación inicial.

Según Rojas y otros. (2011). "Debido a que el informante (cualquier persona que sea entrevistada) es alguien que tiene el conocimiento cultural nativo, el entrevistador no debe predeterminar las respuestas por los tipos de cuestiones preguntadas" ( $p$ 47). Para la presente investigación se aplica entrevista semiestructurada a los padres y representantes, se hace uso de un cuestionario, donde el investigador formula preguntas en relación a la integración de los padres y representantes, y del método Glenn doman, en donde los sujetos investigados proporcionan en forma verbal la información solicitada para posteriormente ser analizada. El instrumento recoge de los padres de familia las expresiones generalizadas y sus realidades para dar interpretación de las actividades que se desarrollan en los hogares correspondientes al seguimiento de la compresión de la lectoescritura.

\section{Resultados}

Una vez cumplida la fase de recolección de datos directamente del objeto de estudio, en este caso específico en el Colegio Gonzalo Rivera Laguado ubicado en Cúcuta, del departamento Norte de Santander, Colombia. Se presentan a continuación los resultados obtenidos, de los participantes en la investigación, en cuadros de análisis categórico con la finalidad de realizar un diagnóstico sobre el conocimiento que poseen los padres y representantes acerca del método Glenn Doman aplicado a la lectoescritura y cómo influyen en el proceso de enseñanza y aprendizaje.

Hablar de participación en los colegios es hablar de democracia; la participación supone que el poder está compartido y que no está en manos de algunos pocos. La tarea de participación y la representación se desarrolla en la vida cotidiana de la institución; si los padres no se sienten miembros de una comunidad educativa, si no se sienten responsables de lo que pasa dentro de ella, la participación no existirá. La participación de los padres en las escuelas exige la transferencia informativa; la posibilidad de elegir libremente, la capacidad real de intervenir en las decisiones de allí su relevancia. Los hallazgos encontrados muestran que la importancia de la participación de los padres de familia al colegio coincide con la valoración de los esfuerzos que hace el docente cuando envía tareas para el hogar, 
sin embargo, manifiestan que no tienen tiempo para dedicarles, que a veces hay demasiadas actividades y el estudiante se cansa para desarrollar el proceso de enseñanza y aprendizaje. Por lo tanto, la planificación y estrategias empleadas por el docente se ven valoradas mas no con incidencia en los padres y representantes, no se logra que se motiven y guíen al estudiante a propiciar el conocimiento para la realización personal y aprendizaje significativo de la lectoescritura.

En consecuencia, se evidencia a continuación las categorías que emergieron:

\section{Interpretación de las categorías emergentes}

Importancia de la participación fenómeno: elementos emergentes participación: valoración, seguimiento del padre, condiciones de estudio, incorporación, apoyos, valoración, intensidad académica.

Fuente: Testimonios (2018).

De ahí la importancia de transformar estrategias para integrar propuestas didácticas que incluyan a los padres y representantes como ente garante complementario en el desarrollo de la lectoescritura de los estudiantes, esto como una solución a los diferentes problemas que presenta el área de lenguaje del Colegio Gonzalo Rivera Laguado. La integración de los padres y representantes debe en ser representativa y que ayude a la transformación del estudiante. Como lo señala Sarjurio y Vera (2001); “el diseño de acciones didácticas puede servir de guía al docente para desarrollar estrategias validas, enmarcadas dentro de su planificación". La importancia que tiene la planificación y el uso de estrategias y herramientas didácticas en el ámbito educativo, puesto que ellas colaboran en fomentar la motivación en los y las estudiantes y a su vez en mantener el interés por los contenidos que se están desarrollando por medio de las actividades de lectoescritura.

\section{Propuesta de acción}

La propuesta que se presenta nace de la situación observada en grado primero del Colegio Gonzalo Rivera Laguado. Se proponen herramientas didácticas basadas en el método global de lectoescritura Glenn Doman para fortalecer el proceso lectoescritor en los estudiantes, para esto se involucran los padres. Los padres y representantes son pieza importante no solo para el cambio y la dinamización de las nuevas tendencias educativas e integradoras, sino sobre todo para mejorar el proceso educativo y desarrollo cognitivo de los estudiantes. El aporte de los padres y representantes a partir de una adecuada participación, se convierte en un elemento de primer orden para concretar las acciones que se diseñan de acuerdo a la planificación del docente de aula, y de ese modo, familia - escuela se conviertan en 
una alianza indisoluble para consolidar las metas que se aspiran alcanzar.

Para dar atención a los padres y representantes se realizaron demostraciones para la ejecución de técnicas de enseñanza y el encuadre psicológico para la introducción del método Glenn Doman con los estudiantes. (Ejercicios para la presentación de rótulos figuras e imágenes). Igualmente se realizaron dramatizaciones con los Padres y representantes sobre diversas situaciones que pueden presentarse en el ambiente familiar, para ser abordadas desde la práctica académica y además de la organización de elementos propios del método con los estudiantes. (Redacción rótulos, impresiones de imágenes asociados a las exigencias del contexto escolar.

\section{Conclusiones}

En la respuesta del planteamiento del problema si se puede fortalecer los procesos de lectoescritura mediante el método Glenn Doman con participación de los padres, en estudiantes de grado primero del colegio Gonzalo Rivera, lo cual se logró mediante una metodología previamente establecida y ordenada.

El impacto de la investigación en la comunidad educativa fue de gran recepción, debido a las incidencias positivas que se generaron en la integración de los padres y representantes con la institución, con los estudiantes y con el docente del grado, mediante estrategias diseñadas a partir del método Glenn doman y el impulso de la compresión de la lectoescritura. Se lograron identificar las debilidades en los estudiantes, encontrando el fenómeno que radica en las estrategias y contenidos que son implementados en el proceso de lectoescritura por medio de los padres y representantes, el cual, no era el más idóneo; debido a que no logra que en los estudiantes surja el interés y la motivación para aprender.

Los hallazgos refirmaron que los padres de familia poseen poco conocimiento del método Glenn Doman por lo que el docente del grado primero, debe reforzar las planificaciones para cumplir con todos los requerimientos cognitivos, axiológicos y prácticos de los estudiantes, interpretando a las características y contextos familiares del estudiante.

Se desarrolla una serie de estrategias que permiten categorizar la aplicación de Doman en el área de la lectoescritura; se asume el proceso dinámico de innovar mediante nuevas prácticas respondiendo a las nuevas exigencias pedagógicas del mundo contemporáneo y por supuesto de los niños, para cambiar paradigmas y adquirir otros; que permita la apropiación del conocimiento en forma creativa y critica donde incluyan un verdadero plan centrado en el desarrollo de competencias 
lectoras y de escritura en los estudiantes.

El conjunto de estrategias didácticas en relación a la implementación del método Glenn Doman en el espacio de aprendizaje se concluye que la propuesta se implementa y se valida, como herramienta pedagógica innovadora y de transformación; de gran relevancia en el proceso de enseñanza y aprendizaje; los padres y representantes, el docente y estudiantes, tienen la pertinencia y disponibilidad de utilizar el método Glenn doman en el ambiente educativo familiar, desde el punto de vista laboral y académico, para mejorar los índices de crecimiento intelectual.

\section{Referencias}

Arnaiz (2003). Clima social familiar de los estudiantes de educación secundaria con dependencia a las redes sociales de la Institución Educativa Particular "Cristo Redentor". Nuevo Chimbote.

Colina R (2012). Análisis teórico sobre la integración productiva como opción para el desarrollo de comunidades rurales. [Documento en línea]. Disponible en: https://www.researchgate.net/ publication/280079271_Analis is_teorico_sobre_la_integracio n_productiva_como_opcion_pa ra_el_desarrollo_de_comunida des_rurales [Consulta: 2018, febrero 12].
CERLALC - UNESO (2012). El libro en cifras. Boletín estadístico del libro en Iberoamérica. Bogotá. CERALC. Recuperado el 31 de enero de 2013 en: http://www.cerlalc.org/files/ta binterno/7ad328_Libro_Cifras _Ago2012.pdf

Flick, U. (2007). Introducción a la investigación cualitativa. España Ediciones Morata.

Garabaya 2016 Participación de los padres de alumnos de educación primaria en las actividades académicas de sus hijos. [Documento en línea]. Disponible en: http://redie.uabc.mx/redie/art icle/view/229/782 [Consulta: 2016, Diciembre 16]

Hohmann, M. y Weikart, D. (2005). La educación de los niños pequeños en acción: Manual para profesionales. Edit. Trillas: México.

Kallarakal (1997) Estrategias para la Integración de las Familias en el Mejoramiento de los Aprendizajes Escolares. Tesis Doctoral publicada. Universidad Nacional de Educación a Distancia. [Documento en línea] Disponible en: http://espacio.uned.es/fez/eserv/tesis uned:EducacionEmmurillo/Documento.pdf. [Consulta: 2018, Enero 2].

Meval (1996), Técnicas y recursos para el aprendizaje Código 427 Selección de Lecturas. 
Universidad Nacional Abierta

Vicerrectorado Académico

Área de Educación Carrera de

Educación Integral:

Licenciatura. Caracas.

Investigacióneducativa. 14(41).

Ochoa (1994),. Integración de la

Familia en el Proceso Educativo

de los Escolares del cuarto

Grado de la Unidad Educativa

nacional "Andrés Bello",

cordero Estado Táchira.

Trabajo de Grado publicado.

Universidad Pedagógica

Experimental Libertador.

[Documento en línea].

Disponible

en:https://fasedeejecuciondeu

nproyectoeducativo.wikispaces

.com/file/view/TRABAJO_FASE

_IV_LDA_VIRGILIA_YORLEY_L

ACRUZ_IMPM_TACHIRA\%5B1\%

5D.doc. [Consulta: 2018, Enero

2]

Rojas de E. B. (2007). Investigación

Cualitativa. Fundamentos y praxis.

Sabino C. (1996). Como hacer una tesis. Editorial Logos. CaracasVenezuela.

Santrock, J.. (2004). Psicología del desarrollo en la adolescencia.

UNESCO-OREALC (2014).

Participación de las familias en la educación infantil latinoamericana. Santiago de Chile. 